\title{
Eight-Year Follow-Up of School-Based Intervention on Childhood Overweight - the Kiel Obesity Prevention Study
}

\author{
Sandra Plachta-Danielzik Beate Landsberg Dominique Lange Jasmin Seiberl \\ Manfred J. Müller \\ Institute of Human Nutrition and Food Science, Christian-Albrechts University of Kiel, Germany
}

\section{Keywords}

Childhood obesity · Prevention - Adolescents .

Behavioural interventions

\section{Summary}

Objective: The aim of this study was to evaluate the 8-year outcome of school-based intervention on weight status, lifestyle and blood pressure (BP) as part of the Kiel Obesity Prevention Study (KOPS). Methods: Within a quasi-randomized controlled trial, 240 intervention (I) and 952 non-intervention (NI) students at age 6 and 14 years were assessed in schools. Six nutrition units followed by 20-min running games were performed within the first year at school. Primary outcome was the 8-year change in body mass index standard deviation score (BMI-SDS) according to German references. Effective intervention was tested using multilevel linear regression analysis. Results: Eight-year changes in BMISDS were +0.18 and +0.22 with increases in prevalence of overweight from 8.3 to $10.4 \%$ and 7.0 to $11.2 \%$ in I and $\mathrm{NI}$ students, respectively. Cumulative 8-year incidence of overweight was $5.9 \%$ and $7.1 \%$ in I and $\mathrm{NI}$ students, respectively. There was no overall effect of intervention, but a significant interaction was shown between the intervention and the socio-economic status (SES), which demonstrated that in high SES, the 8-year change in BMI-SDS was in favour of I $(-0.17$ in I and +0.17 in $\mathrm{NI}$; $p<0.01$ ). Intervention had no measurable effects on lifestyle and BP. Conclusions: School-based health promotion has some favourable and sustained effects on 8-year changes in BMI-SDS, which are most pronounced in students of high SES families. The data argue in favour of further preventive measures.

\section{Introduction}

Childhood obesity is a major public health problem. Since treatment of obesity is difficult and showed low success rates [1], preventive measures are necessary. Within the last years, many preventive programs were conducted in Germany as well as worldwide [2-6]. These data gave evidence for small or even no effect on childhood overweight. However, most of these programs were uncontrolled, and short-term effects were evaluated only. By contrast, long-term effects of schoolbased interventions to prevent childhood overweight have been rarely investigated. In a recent systematic review of school-based interventions to prevent childhood obesity, 38 studies were identified of which only 14 studies had a followup period of more than 1 year [2]. Of these 14 studies, 8 studies had a follow-up period of 2 years, and 3 further studies of 3 years. Four-year follow-up data of school-based intervention were published for the Kiel Obesity Prevention Study (KOPS) [7] as well as for the Swedish STOPP study [8]. Within the Cretan Health and Nutrition Education Program, children were followed for up to 10 years [9]. This program revealed that changes in blood pressure, body mass index (BMI) z-score, some dietary indices as well as physical activity were in favour of the intervention group when compared with the control group. The importance of long-term evaluations over several years is reflected by the results of the French EPODE study [10]: In the North French population, there was no effect between the intervention and control group after 4 years but 12-year follow-up data showed a significant lower prevalence of overweight in the intervention group when compared to the control group. These data argue in favour of long-term success rates which might have been overlooked in short-term intervention studies.

\section{KARGER \\ Fax +497614520714 \\ Information@Karger.de}

www.karger.com
(C) 2011 S. Karger GmbH, Freiburg

1662-4025/11/0041-0035\$38.00/0

Accessible online at:

www.karger.com/ofa
Prof. Dr. med. Manfred James Müller

Institute of Human Nutrition and Food Science

Christian-Albrechts University

Düsternbrooker Weg 17, 24105 Kiel, Germany

FAX +494318805679

mmueller@nutrfoodsc.uni-kiel.de 
Within KOPS, a school-based intervention was started in 1996 and students were followed over 8 years [11]. At 1-year follow-up, intervention had significant effects on increases in median triceps skin folds of the whole group as well as percentage body fat mass (\%FM) of overweight children [11]. Four-year follow-up data only showed selective effects due to socio-economic status (SES) and parental body weight: when compared with non-intervention children increases in prevalence and cumulative 4-year incidence of overweight were lower in intervention children of high SES and children of normal weight mothers [7]. Altogether the KOPS experience suggests some but selective effects of school-based prevention of childhood overweight. To address sustainability, we now present 8-year follow-up data of KOPS.

\section{Material and Methods}

\section{Study Population}

Between 1996 and 2001 we enrolled 4,997 6-year-old children during the school entry examinations, i.e. $41 \%$ of the total population $(n=12,254$ born in Kiel between 1990 and 1995). There were no eligibility criteria except willingness to participate. All parents gave their informed written consent. The study was approved by the local ethical committee. The KOPS cohort was representative for all 6-year-old children in Kiel (prevalence of overweight: $12.8 \%$ in KOPS; $11.8 \%$ in the total population; low/ middle/high SES: $46.8 / 20.7 / 32.5 \%$ in KOPS; $45.8 / 20.5 / 33.8 \%$ in the total population) [12]. A total of 1,192 of our initial population (24\%) could be re-investigated at the age of 14 years.

\section{Measurements}

Anthropometric (height, weight, waist circumference (WC)) as well as tetra-polar bioelectrical impedance analysis (BIA) (fat mass calculated with a population specific algorithm) measurements were performed by trained nutritionists [13]. A questionnaire (answered by the parents for 6 -year-olds and by the adolescents themselves, response rate $55 \%$ ) addressed i) diet, ii) physical activity and inactivity, iii) self-reported weight and height of parents, and iv) parental education. Blood pressure was measured using a sphygmomanometer on the right arm after a 5-min rest in the 14-year-old students.

\section{Study Design}

School-based intervention was performed between 1996 and 2001 in 2-4 'intervention schools' per year. The schools were randomly assigned to the intervention and non-intervention group. Randomisation (selection of a random sample of schools performed with SPSS) and characteristics of schools have been described in detail previously [7]. Fourteen of 32 schools in Kiel served as 'intervention schools' where 780 first graders were addressed (T0). In the following years, former 'intervention schools' served as 'non-intervention schools'. After 8 years (T1), 240 students ( = I, 30.8\%) were re-investigated. The data of these students were compared with longitudinal data on children from 'non-intervention schools' (= NI, $\mathrm{n}=952)$. To analyze effectiveness, T1-T0 changes in variables were considered. Eight-year change in BMI standard deviation score (BMI-SDS) was the primary outcome. WC and \%FM were considered as secondary outcome parameters. The effect of intervention on lifestyle variables and blood pressure was analyzed in a subgroup of 651 ((120 I; $531 \mathrm{NI})$ and 1,189 (239 I; $950 \mathrm{NI})$ students, respectively. All investigations were blinded, i.e. examiners could not identify intervention children.

\section{Intervention}

All first graders of 'intervention schools' were addressed by 6 nutrition units performed during 2-3 weeks within the second term of the first school year. Messages were i) to eat fruit and vegetable every day, ii) to reduce intake of high fat foods, iii) to keep active at least $1 \mathrm{~h}$ a day, and iv) to decrease TV consumption to less than $1 \mathrm{~h}$ per day. Messages were conveyed by use of nutrition fairy tales, interactive games as well as by preparing a healthy breakfast. After each unit, running games were offered for $20 \mathrm{~min}$ on the school yard. Games and recipes for a healthy breakfast should be implemented in the school routine. Parents were informed during a parental school meeting. Teachers were trained within a half-day structured nutrition education program (for further information on the intervention see [7]).

\section{Outcome Parameters}

\section{Weight Status}

BMI-SDS and overweight (BMI $\geq 90$ th percentile) were calculated according to actual German BMI reference percentiles [14]. Due to missing German reference values on \%FM and WC, z-scores of \%FM and WC were calculated based on the KOPS cohorts of 6- and 14-year-old students. The time span between $\mathrm{T} 0$ and $\mathrm{T} 1$ was $8.3 \pm 0.4$ years. T1 data were corrected to 8 years by linear extrapolation using the following equation: e.g. $\mathrm{BMI}_{\text {corrected }}(\mathrm{T} 1)=((\mathrm{BMI}(\mathrm{T} 1)-\mathrm{BMI}(\mathrm{T} 0)) /($ age $(\mathrm{T} 1)-$ age $(\mathrm{T} 0)) * 8)+\mathrm{BMI}(\mathrm{T} 0)$.

Table 1. Analysis of dropouts for all students as well as students stratified for intervention (I) and non-intervention (NI)

\begin{tabular}{|c|c|c|c|c|c|c|}
\hline & \multirow[t]{2}{*}{ Participants, all } & \multirow[t]{2}{*}{ Dropout, all } & \multicolumn{2}{|l|}{ Participants } & \multicolumn{2}{|l|}{ Dropout } \\
\hline & & & I & NI & I & NI \\
\hline $\mathrm{n}$ & 1,192 (23.9\%) & $3,805(76.1 \%)$ & $240(30.1 \%)^{b}$ & $952(22.7 \%)^{\mathrm{b}}$ & $558(69.9 \%)^{\mathrm{b}}$ & $3,247(77.3 \%)^{b}$ \\
\hline Boys/girls, \% & $46.4^{\mathrm{a}} / 53.6^{\mathrm{a}}$ & $51.2 / 48.8$ & $45.8 / 54.2$ & $46.5 / 53.5$ & $53.2 / 46.8$ & $50.9 / 49.1$ \\
\hline Overweight, \% & $7.3^{\mathrm{a}}$ & $13.5^{\mathrm{a}}$ & 8.3 & 7.0 & 15.2 & 13.2 \\
\hline \multicolumn{7}{|l|}{ SES } \\
\hline Low, \% & $18.9^{\mathrm{a}}$ & $40.0^{\mathrm{a}}$ & 18.3 & 19.0 & 40.5 & 39.9 \\
\hline Middle, \% & $34.7^{\mathrm{a}}$ & $23.9^{\mathrm{a}}$ & 36.3 & 34.3 & 22.6 & 24.1 \\
\hline High, \% & $46.4^{\mathrm{a}}$ & $36.1^{\mathrm{a}}$ & 45.4 & 46.6 & 36.9 & 36.0 \\
\hline Overweight mothers, \% & $25.9^{\mathrm{a}}$ & $33.1^{\mathrm{a}}$ & 21.4 & 27.0 & 32.1 & 33.2 \\
\hline
\end{tabular}

${ }^{a}$ Significant differences between participants and dropouts (chi ${ }^{2}$-test, $\mathrm{p}<0.05$ ).

${ }^{\mathrm{b}}$ Significant differences between I and NI $\left(\mathrm{chi}^{2}\right.$-test, $\left.\mathrm{p}<0.05\right)$. 
Table 2. Characterisation of the study population before (T0) and after 8-year observation period (T1) (data are given as median (interquartile range) weighted on the reference population $\left.{ }^{a}\right)$

\begin{tabular}{|c|c|c|c|c|c|c|c|}
\hline & \multicolumn{3}{|l|}{$\mathrm{I}(\mathrm{n}=240)$} & \multicolumn{3}{|l|}{$\mathrm{NI}(\mathrm{n}=952)$} & \multirow[t]{2}{*}{$\Delta\left(\mathrm{I}_{\mathrm{T} 1-\mathrm{T} 0}-\mathrm{NI}_{\mathrm{T} 1 \mathrm{~T} 0}\right)$} \\
\hline & $\mathrm{T} 0$ & $\mathrm{~T} 1$ & $\Delta(\mathrm{T} 1-\mathrm{T} 0)$ & T0 & $\mathrm{T} 1$ & $\Delta(\mathrm{T} 1-\mathrm{T} 0)$ & \\
\hline Boys/girls, \% & & $48.7 / 51.3$ & & & $50.3 / 49.7$ & & \\
\hline SES low/ middle/high, \% & & $24.8 / 33.2 / 42.0$ & & & $26.0 / 31.9 / 42.2$ & & \\
\hline Overweight mother, \% & & 22.7 & & & 28.7 & & \\
\hline Age, years & $\begin{array}{l}6.3 \\
(5.9-6.5)\end{array}$ & $\begin{array}{l}14.3 \\
(13.9-14.5)\end{array}$ & $\begin{array}{l}8.0 \\
(0.0)\end{array}$ & $\begin{array}{l}6.3 \\
(6.0-6.5)\end{array}$ & $\begin{array}{l}14.3 \\
(14.0-14.5)\end{array}$ & $\begin{array}{l}8.0 \\
(0.0)\end{array}$ & 0.0 \\
\hline Height, m & $\begin{array}{l}1.19^{\mathrm{b}} \\
(1.16-1.23)\end{array}$ & $\begin{array}{l}1.66^{\mathrm{b}} \\
(1.60-1.71)\end{array}$ & $\begin{array}{l}0.46 \\
(0.42-0.50)\end{array}$ & $\begin{array}{l}1.21^{\mathrm{b}} \\
(1.17-1.24)\end{array}$ & $\begin{array}{l}1.67^{\mathrm{b}} \\
(1.62-1.73)\end{array}$ & $\begin{array}{l}0.47 \\
(0.43-0.50)\end{array}$ & -0.01 \\
\hline Weight, kg & $\begin{array}{l}22.3 \\
(20.5-24.5)\end{array}$ & $\begin{array}{l}56.2 \\
(51.3-63.5)\end{array}$ & $\begin{array}{l}34.0 \\
(29.7-40.1)\end{array}$ & $\begin{array}{l}22.0 \\
(20.5-24.8)\end{array}$ & $\begin{array}{l}57.0 \\
(51.3-64.0)\end{array}$ & $\begin{array}{l}34.5 \\
(30.0-40.2)\end{array}$ & -0.5 \\
\hline BMI, $\mathrm{kg} / \mathrm{m}^{2}$ & $\begin{array}{l}15.6 \\
(14.7-16.9)\end{array}$ & $\begin{array}{l}20.3 \\
(18.9-22.5\end{array}$ & $\begin{array}{l}4.6 \\
(3.5-6.2)\end{array}$ & $\begin{array}{l}15.4 \\
(14,616.5)\end{array}$ & $\begin{array}{l}20.0 \\
(18.7-22.3)\end{array}$ & $\begin{array}{l}4.7 \\
(3.5-6.3)\end{array}$ & -0.1 \\
\hline BMI-SDS & $\begin{array}{l}0.10^{\mathrm{b}} \\
(-0.50-0.78)\end{array}$ & $\begin{array}{l}0.20 \\
(-0.31-0.93)\end{array}$ & $\begin{array}{l}0.18 \\
(-0.39-0.67)\end{array}$ & $\begin{array}{l}-0.05^{\mathrm{b}} \\
(-0.62-0.57)\end{array}$ & $\begin{array}{l}0.15 \\
(-0.35-0.84)\end{array}$ & $\begin{array}{l}0.22 \\
(-0.26-0.69)\end{array}$ & -0.04 \\
\hline $\mathrm{FM}_{\mathrm{BIA}}, \%$ & $\begin{array}{l}21.0 \\
(16.2-25.5)\end{array}$ & $\begin{array}{l}23.1 \\
(16.8-27.9)\end{array}$ & $\begin{array}{l}1.9 \\
(-3.03-6.6)\end{array}$ & $\begin{array}{l}20.9 \\
(16.5-25.7)\end{array}$ & $\begin{array}{l}22.3 \\
(16.6-27.6)\end{array}$ & $\begin{array}{l}1.5 \\
(-3.6-6.3)\end{array}$ & -0.4 \\
\hline z-score ${ }^{a}$ FM $_{\text {BIA }}$ & $\begin{array}{l}-0.09 \\
(-0.80-0.51)\end{array}$ & $\begin{array}{l}-0.06 \\
(-0.61-0.67)\end{array}$ & $\begin{array}{l}0.16 \\
(-0.46-0.89)\end{array}$ & $\begin{array}{l}-0.10 \\
(-0.71-0.54)\end{array}$ & $\begin{array}{l}-0.05 \\
(-0.62-0.66)\end{array}$ & $\begin{array}{l}0.14 \\
(-0.50-0.77)\end{array}$ & -0.2 \\
\hline $\mathrm{WC}, \mathrm{cm}$ & $\begin{array}{l}55.0 \\
(52.0-58.0)\end{array}$ & $\begin{array}{l}69.0 \\
(66.1-74.3)\end{array}$ & $\begin{array}{l}14.6 \\
(11.9-17.9)\end{array}$ & $\begin{array}{l}54.0 \\
(52.0-57.0)\end{array}$ & $\begin{array}{l}69.6 \\
(65.9-74.9)\end{array}$ & $\begin{array}{l}15.4 \\
(12.0-19.0)\end{array}$ & -0.8 \\
\hline z-score ${ }^{a}$ WC & $\begin{array}{l}-0.21 \\
(-0.63-0.33)\end{array}$ & $\begin{array}{l}-0.26 \\
(-0.66-0.48)\end{array}$ & $\begin{array}{l}-0.03 \\
(-0.51-0.45)\end{array}$ & $\begin{array}{l}-0.29 \\
(-0.71-0.30)\end{array}$ & $\begin{array}{l}-0.22 \\
(-0.67-0.45)\end{array}$ & $\begin{array}{l}0.08 \\
(-0.40-0.60)\end{array}$ & -0.11 \\
\hline
\end{tabular}

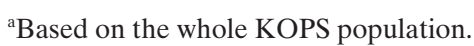

${ }^{\mathrm{b}}$ Significant difference between intervention (I) and non-intervention (NI) group; Mann-Whitney test $(\mathrm{p}<0.05)$.

$\mathrm{SES}=$ Socioeconomic status; BMI-SDS = standard deviation score of $\mathrm{BMI} ; \mathrm{FM}_{\mathrm{BIA}}$ = fat mass as measured by bioelectrical impedance analysis;

$\mathrm{WC}=$ waist circumference.

Lifestyle Variables

Food intake was assessed by a validated food frequency questionnaire, and a dietary pattern index was calculated [15]. Regular sport activities (high: > $1 \mathrm{~h}$ per week in 6-year-olds; $>3 \mathrm{~h}$ per week in 14-year-olds) and inactivity (watching TV or playing computer games, high: $>1 \mathrm{~h}$ media time per day in 6-year-olds; $>3 \mathrm{~h}$ per day in 14-year-olds) were assessed using a validated questionnaire [16]. Lifestyle factors were reported by parents for the 6-year-olds and self-reported by the adolescents.

\section{Blood Pressure}

Hypertension was defined by the age-specific 95th percentile for systolic and/or diastolic blood pressure as recommended by the Second Task Force on Blood Pressure Control in Children [17].

\section{Analysis of Dropouts}

Students who were re-investigated after 8 years ( = participants) were more often female and had a lower prevalence of overweight as well as overweight mothers and belonged more often to high SES when compared with students who were investigated at age 6 years only ( = dropouts) (table 1). Due to the selection bias, data were weighted on the distribution of the whole KOPS cohort with regard to weight status of the children and SES. However, within participants and dropouts, there were no significant differences between I and NI students (table 1). The dropout rate was significantly higher in NI than in I (77.3 vs. $69.9 \%)$.

\section{Statistics}

Statistical analysis was performed with SPSS 15.0 for Windows (SPSS Inc., Chicago, IL, USA) and STATA 11 (College Station, TX, USA). Results were presented as median and interquartile range (IQR). The nonparametric Mann-Whitney U-test and the chi-square test were used to determine between-group differences in continuous and categorical variables, respectively.

\section{Multivariate Analysis}

Randomization was done at school level. A multilevel approach was used due to the hierarchically data structure (level 1: students, level 2: schools). Multilevel linear regression analyses on 8-year changes in BMI-SDS, z-score of FM and WC were performed using school-based intervention, BMI-SDS at baseline, z-score of FM and WC at baseline, sex, SES, and BMI of the mothers as dependent variables as well as schools as cluster variable (XTMIXED command in STATA). In addition, interaction terms between school-based intervention and sex, SES, and BMI of the 
Table 3. Multilevel ${ }^{\mathrm{a}}$ linear regression analysis on 8-year changes in BMI-SDS, z-score of fat mass (FM) and waist circumference (WC) in intervention and non-intervention students

\begin{tabular}{|c|c|c|c|c|c|c|}
\hline \multirow[t]{2}{*}{ Independent variables } & \multicolumn{2}{|c|}{$\begin{array}{l}\text { Dependent variable } \\
\text { 8-year change in BMI-SDS }\end{array}$} & \multicolumn{2}{|c|}{ 8-year change in z-score FM } & \multicolumn{2}{|c|}{ 8-year change in z-score WC } \\
\hline & $\beta$-coefficient ${ }^{\mathrm{b}} \pm \mathrm{SE}$ & $\mathrm{p}$ & $\beta$-coefficient ${ }^{\mathrm{b}} \pm \mathrm{SE}$ & $\mathrm{p}$ & $\beta$-coefficient ${ }^{\mathrm{b}} \pm \mathrm{SE}$ & $\mathrm{p}$ \\
\hline Intervention & $0.435 \pm 0.39$ & 0.266 & $0.416 \pm 0.49$ & 0.396 & $0.046 \pm 0.44$ & 0.917 \\
\hline BMI-SDS / z-score of FM / WC at baseline ${ }^{c}$ & $-0.372 \pm 0.02$ & 0.000 & $-0.514 \pm 0.03$ & 0.000 & $-0.345 \pm 0.03$ & 0.000 \\
\hline Sex & $-0.026 \pm 0.04$ & 0.564 & $0.002 \pm 0.06$ & 0.966 & $-0.015 \pm 0.05$ & 0.770 \\
\hline SES & $-0.071 \pm 0.03$ & 0.020 & $-0.120 \pm 0.04$ & 0.002 & $-0.044 \pm 0.03$ & 0.209 \\
\hline BMI of mothers & $0.025 \pm 0.01$ & 0.000 & $0.033 \pm 0.01$ & 0.000 & $0.022 \pm 0.01$ & 0.000 \\
\hline Intervention $\times \operatorname{sex}$ & $0.048 \pm 0.10$ & 0.636 & $0.020 \pm 0.13$ & 0.874 & $-0.024 \pm 0.11$ & 0.830 \\
\hline Intervention $\times \mathrm{SES}$ & $-0.159 \pm 0.07$ & 0.020 & $-0.131 \pm 0.09$ & 0.129 & $-0.108 \pm 0.08$ & 0.161 \\
\hline Intervention $\times \mathrm{BMI}$ of mothers & $-0.007 \pm 0.01$ & 0.572 & $-0.005 \pm 0.02$ & 0.769 & $-0.006 \pm 0.01$ & 0.673 \\
\hline
\end{tabular}

${ }^{a}$ All analyses are adjusted for clustering effect in schools.

bignificant $\beta$-coefficients are printed in italics.

${ }^{\mathrm{c}} \mathrm{BMI}-\mathrm{SDS}: \mathrm{R}^{2}=0.307$. FM: $\mathrm{R}^{2}=0.271$; WC: $\mathrm{R}^{2}=0.132$.

mothers were considered. In the analyses of co-morbidities, systolic and diastolic blood pressures were log-transformed to normalize data. Level of significance was set at $\mathrm{p}<0.05$ (two-sided).

\section{Statistical Power Analysis}

KOPS was designed to be large enough to detect a mean difference in BMI-SDS of 0.1 (or $0.3 \mathrm{BMI}$ units or $0.84 \mathrm{~kg}$ ) with a power of $80 \%$ at the two-tailed significance level. To reach this, 235 I and 947 NI students were needed. Sample size calculation was performed with Win Episcope 2.0.

\section{Intention to Treat Analysis}

To assess the potential effect of selective dropout, we conducted an intention to treat' analysis. Multilevel linear regression analyses on 8-year changes in BMI-SDS were performed based on three assumptions regarding dropouts. First, all dropouts became or stayed overweight (scenario 1); second, all dropouts became or stayed normal weight (scenario 2); and third, none of the dropouts changed their weight status (scenario 3). Estimation of 8-year changes in BMI-SDS for dropouts were done according to mean changes in BMI-SDS in participants: persistent normal weight students: +0.20 , incident overweight and persistent overweight students: +1.13 , remittent normal weight students: -0.87 .

\section{Results}

\section{Characteristics of the Study Population}

Weight status of I students was compared with the weight status of NI students (table 2). Baseline data as well as 8-year followup data are presented; 8 -year changes $(\Delta \mathrm{T} 1-\mathrm{T} 0)$ were calculated. Distribution of sex, SES, and weight status of the mothers did not differ between I and NI. At T0 I students were taller and had a lower BMI-SDS when compared with NI students. At T1, I students were still taller than NI students. BMI at baseline ( $p=0.056), 8$-year changes in WC $(p=0.086)$ and $z$-score of WC $(p=0.071)$ tended to be lower in the intervention group.

\section{Eight-Year Changes in Weight Status}

Prevalence of overweight increased from 8.3 to $10.4 \%$ and from 7.0 to $11.2 \%$ in I and NI students, respectively. The

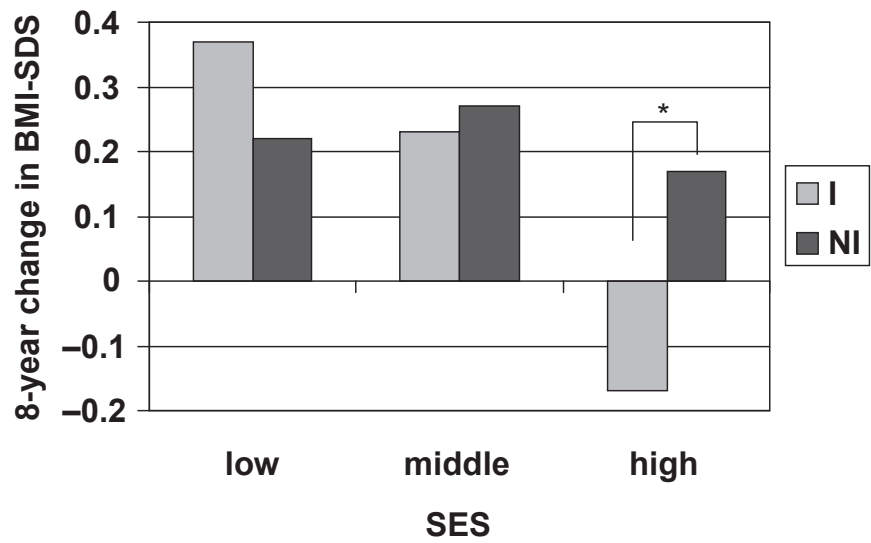

Fig. 1. Eight-year changes in BMI-SDS in intervention (I) and non-intervention (NI) students stratified according to socio-economic status (SES). *Mann-Whitney test, $\mathrm{p}<0.001$.

cumulative 8-year incidence of overweight was 5.9 and $7.1 \%$ in I and NI students. The 8-year cumulative remission of overweight was 40.0 and $34.3 \%$ in I and NI students, respectively. A multilevel linear regression analysis was performed with changes in BMI-SDS as dependent variable (table 3). BMI-SDS at baseline, SES, and BMI of the mothers significantly influenced 8-year changes in BMI-SDS. Students with a high BMI-SDS at baseline had smaller 8-year changes than students with a lower BMI-SDS at baseline. With increasing SES, 8-year change in BMI-SDS was decreasing. The higher the BMI of the mothers, the higher was the 8-year change in BMI-SDS in the students. In addition, the interaction between intervention and SES was significant, i.e. the effect of intervention was different in different SES groups. To better characterize the direction of effect, figure 1 shows the mediator effect. Eight-year changes in BMI-SDS were significantly lower in I students of high SES families when compared with NI students of high SES families $(-0.17(-0.58-0.44)$ and 
Table 4. Prevalence of lifestyle habits (dietary pattern index (DPI), physical activity, inactivity) before (baseline) and 8 years after intervention in intervention (I) and non-intervention (NI) students in all students ( $\mathrm{n}=116$ in $\mathrm{I}, \mathrm{n}=498$ in NI) and stratified by SES (low: $\mathrm{n}=25$ in I, $\mathrm{n}=110$ in NI; middle: $\mathrm{n}=37$ in $\mathrm{I}, \mathrm{n}=147$ in NI; high: $\mathrm{n}=54$ in $\mathrm{I} ; \mathrm{n}=241$ in NI)

\begin{tabular}{|c|c|c|c|c|c|c|c|}
\hline & \multicolumn{2}{|c|}{ Baseline } & \multicolumn{2}{|c|}{ 8-year follow-up } & \multicolumn{2}{|c|}{$\Delta$ follow-up - baseline } & \multirow[t]{2}{*}{$\Delta \mathrm{I}-\mathrm{NI}$} \\
\hline & I & NI & I & NI & I & NI & \\
\hline \multicolumn{8}{|l|}{ DPI, \% } \\
\hline Healthy & 34.2 & 40.5 & 37.9 & 40.8 & 3.7 & 0.3 & 3.4 \\
\hline Mixed & 60.7 & 50.8 & 45.4 & 44.7 & -15.3 & -6.1 & -9.2 \\
\hline Risky & 5.1 & 8.7 & 16.7 & 14.5 & 11.6 & 5.8 & 5.8 \\
\hline \multicolumn{8}{|c|}{ Physical activity, \% } \\
\hline High & 37.2 & 37.8 & 39.4 & 36.0 & 2.2 & -1.8 & 4.0 \\
\hline Low & 62.8 & 62.2 & 60.6 & 64.0 & -2.2 & 1.8 & -4.0 \\
\hline \multicolumn{8}{|l|}{ Inactivity, $\%$} \\
\hline Low & 69.6 & 72.0 & 75.4 & 75.2 & 5.8 & 3.2 & 2.6 \\
\hline High & 30.4 & 28.0 & 24.6 & 24.8 & -5.8 & -3.2 & -2.6 \\
\hline \multicolumn{8}{|c|}{ DPI low SES, \% } \\
\hline Healthy & 20.3 & 34.1 & 14.8 & 34.0 & -5.5 & -0.1 & -5.4 \\
\hline Mixed & 79.7 & 56.5 & 45.3 & 45.3 & -34.4 & -11.2 & -23.2 \\
\hline Risky & 0 & 9.4 & 39.8 & 20.7 & 39.8 & 11.3 & 28.5 \\
\hline \multicolumn{8}{|c|}{ DPI middle SES, \% } \\
\hline Healthy & 28.6 & 38.3 & 46.4 & 43.3 & 17.8 & 5.0 & 12.8 \\
\hline Mixed & 64.2 & 52.2 & 44.1 & 43.8 & -20.1 & -8.4 & -11.7 \\
\hline Risky & 7.3 & 9.5 & 9.5 & 12.9 & 2.2 & 3.4 & -1.2 \\
\hline \multicolumn{8}{|c|}{ DPI high SES, \% } \\
\hline Healthy & 44.3 & 44.8 & 42.7 & 42.4 & -1.6 & -2.4 & 0.8 \\
\hline Mixed & 49.7 & 47.3 & 46.3 & 45.0 & -3.4 & -2.3 & -1.1 \\
\hline Risky & 6.1 & 7.8 & 11.0 & 12.6 & 4.9 & 4.8 & 0.1 \\
\hline \multicolumn{8}{|c|}{ Physical activity low SES, \% } \\
\hline High & 14.8 & 29.2 & 19.5 & 24.6 & 4.7 & -4.6 & 9.3 \\
\hline Low & 85.2 & 70.8 & 80.5 & 75.4 & -4.7 & 4.6 & -9.3 \\
\hline \multicolumn{8}{|c|}{ Physical activity middle SES, \% } \\
\hline High & 50.0 & 39.0 & 41.0 & 31.1 & -9.0 & -7.9 & -1.1 \\
\hline Low & 50.0 & 61.0 & 59.0 & 68.9 & 9.0 & 7.9 & 1.1 \\
\hline \multicolumn{8}{|c|}{ Physical activity low SES, \% } \\
\hline High & 41.6 & 42.0 & 47.9 & 43.9 & 6.6 & 1.9 & 4.4 \\
\hline Low & 58.4 & 58.0 & 52.1 & 56.1 & -6.3 & -1.9 & -4.4 \\
\hline \multicolumn{8}{|c|}{ Inactivity low SES, \% } \\
\hline Low & 45.3 & 45.5 & 60.2 & 67.8 & 14.9 & 22.3 & -7.4 \\
\hline High & 54.7 & 54.5 & 39.8 & 32.2 & -14.9 & -22.3 & 7.4 \\
\hline \multicolumn{8}{|c|}{ Inactivity middle SES, \% } \\
\hline Low & 57.1 & 71.6 & 79.4 & 73.3 & 22.3 & 1.7 & 20.6 \\
\hline High & 42.9 & 28.4 & 20.6 & 26.7 & -22.3 & -1.7 & -20.6 \\
\hline \multicolumn{8}{|c|}{ Inactivity high SES, \% } \\
\hline Low & 81.2 & 84.3 & 73.4 & 79.1 & -7.8 & -5.2 & -2.6 \\
\hline High & 18.8 & 15.7 & 26.6 & 20.9 & 7.8 & 5.2 & 2.6 \\
\hline
\end{tabular}

No significant differences between intervention and non-intervention group; chi $^{2}$-test $(\mathrm{p}>0.05)$.

$+0.17(-0.29-0.60)$ in I and NI, respectively; $\mathrm{p}<0.01)$. Multilevel linear regression analysis was repeated using 8-year change in $\mathrm{z}$-score of \% FM and $\mathrm{WC}$ as dependent variable (table 3). The baseline value of the dependent variable as well as BMI of the mothers were significant determinants. SES also explained variance of 8-year changes in z-score of \%FM. An effect of intervention could not be shown in these analyses. 
Table 5. Blood pressure (median (interquartile range) and prevalence of elevated values $\left.{ }^{\mathrm{a}}\right)$ in intervention (I) and non-intervention (NI) students 8 years after school-based intervention

\begin{tabular}{|c|c|c|}
\hline & I & NI \\
\hline \multicolumn{3}{|l|}{ Blood pressure } \\
\hline Number of students & 239 & 950 \\
\hline Systolic, $\mathrm{mm} \mathrm{Hg}$ & $118(110-124)$ & $120(110-125)$ \\
\hline Diastolic, $\mathrm{mm} \mathrm{Hg}$ & $72(68-80)$ & $74(68-80)$ \\
\hline Systolic elevated, \% & 6.7 & 7.5 \\
\hline Diastolic elevated, \% & 6.0 & 8.4 \\
\hline Systolic and/or diastolic elevated, \% & 10.8 & 13.3 \\
\hline \multicolumn{3}{|l|}{ Low SES } \\
\hline Number of students & 58 & 238 \\
\hline Systolic, mm Hg & $115(110-124)$ & $120(110-125)$ \\
\hline Diastolic, $\mathrm{mm} \mathrm{Hg}$ & $72(65-80)$ & $74(68-80)$ \\
\hline Systolic elevated, \% & 2.0 & 5.1 \\
\hline Diastolic elevated, \% & 11.5 & 7.1 \\
\hline Systolic and/or diastolic elevated, \% & 13.5 & 11.1 \\
\hline \multicolumn{3}{|l|}{ Middle SES } \\
\hline Number of students & 77 & 292 \\
\hline Systolic, mm Hg & $118(112-115)$ & $120(110-126)$ \\
\hline Diastolic, $\mathrm{mm} \mathrm{Hg}$ & $75(70-80)$ & $75(68-80)$ \\
\hline Systolic elevated, \% & 10.7 & 10.8 \\
\hline Diastolic elevated, \% & 3.9 & 10.6 \\
\hline Systolic and/or diastolic elevated, \% & 13.4 & 16.8 \\
\hline \multicolumn{3}{|l|}{ High SES } \\
\hline Number of students & 97 & 385 \\
\hline Systolic, $\mathrm{mm} \mathrm{Hg}$ & $120(110-124)$ & $120(110-125)$ \\
\hline Diastolic, $\mathrm{mm} \mathrm{Hg}$ & $72(69-78)$ & $73(68-80)$ \\
\hline Systolic elevated, \% & 6.3 & 6.5 \\
\hline Diastolic elevated, \% & 4.5 & 7.6 \\
\hline Systolic and/or diastolic elevated, \% & 7.2 & 12.1 \\
\hline
\end{tabular}

${ }^{a}$ According to recommendations of the American Academy of Pediatrics, 1987.

No significant difference between intervention and non-intervention group, Mann-Whitney-test and chi $^{2}$-test $(\mathrm{p}>0.05)$.

\section{Intension to Treat Analysis}

In all 3 scenarios, the interaction between school-based intervention and SES remained significant $(\beta$ coefficient \pm standard error, $\mathrm{p}$ value: for scenario $1:-0.060 \pm 0.03, \mathrm{p}=0.018$; for scenario $2:-0.050 \pm 0.02, p=0.013$; for scenario $3:-0.060 \pm$ $0.03, \mathrm{p}=0.018)$.

\section{Lifestyle Habits}

Table 4 shows prevalence of lifestyle habits in I and NI students before and 8 years after intervention. Lifestyle habits were similar in I and NI students. However, 8-year changes in healthy dietary patterns, physical activity, and media time consumption tended to be better in I when compared to NI. Stratifying data according to SES (table 4) showed that 8-year changes in the dietary pattern index tended to be better in high SES when compared to low SES. Differences between I and NI were highest in low SES. Eight-year changes in physical activity were similar in all SES groups but differences between I and NI were highest in low SES. Changes in inactivity were mainly seen in low SES but a successful intervention was seen in students from middle SES only.

\section{Blood Pressure}

At age 14 years, blood pressure was higher in overweight students when compared with normal weight students (systolic: 125 (120-130) mm Hg versus 120 (110-125) mm Hg, p < 0.05; diastolic: 78 (70-82) $\mathrm{mm} \mathrm{Hg}$ versus 72 (68-80) mm Hg; $\mathrm{p}<0.05)$. Blood pressure was significantly correlated with BMI-SDS (systolic: $r=0.237$, diastolic: $r=0.200 ; p<0.000$ for both), z-score of \%FM (systolic: $\mathrm{r}=0.173$, diastolic: $\mathrm{r}=0.174$; $\mathrm{p}<$ 0.000 for both) and WC (systolic: $r=0.282$, diastolic: $r=0.210$; $\mathrm{p}<0.000$ for both) at age 14 years. Correlation coefficients of BMI-SDS and z-score of WC were comparable whereas the correlation coefficients of z-score of \%FM to blood pressure were lower. Eight-year changes in BMI-SDS and z-score of WC were correlated with blood pressure (systolic: $r=0.142$ and $r=0.186$, diastolic: $r=0.108$ and $r=0.120$ for $\Delta$ BMI-SDS and $\Delta \mathrm{z}$-score WC, respectively; $\mathrm{p}<0.000$ for all). Eight-year changes in \%FM showed a correlation to systolic blood pressure only $(r=0.084, p=0.005)$. In 14-year-old students, there were no significant differences in systolic and diastolic blood pressure between I and NI students (table 5). However, prevalence of high blood pressure tended to be lower in I when 
compared with NI. An inverse social gradient in prevalence of elevated systolic and/or diastolic blood pressure was seen in I students but not in NI students (table 5). None of the SES groups showed significant differences in blood pressure between I and NI.

\section{Discussion}

The long-term follow-up data of KOPS showed that schoolbased health promotion had some favourable and sustained effects on BMI. However, the effect was seen in students of high SES families only (table 3, fig. 1). This is in line with the SES selective effect of intervention seen in the 4-year followup data of KOPS [7]. By contrast, our previously observed effect in children of normal weight mothers is lost after 8 years of follow-up. Selective effects of intervention have also been described by other authors. Some of the interventions were successful in girls only [18-22], whereas in one study only boys were successful [23]. Ethnic differences were found in an American study [24] as well as in a German study [25]. However up to now none of the studies and also none of the numerous reviews published so far have addressed the issue of SES selective effects of preventive measures. This is surprising since a low SES was already shown as a barrier of familybased intervention [26]. Because of the inverse social gradient in overweight, a very recent German intervention study was conducted in low SES areas [25]. Accordingly, this intervention was effective in non-immigrants only. All these data suggest that further primary prevention programmes have to be tailored to the individual needs and contexts of children and adolescents.

\section{Different Parameters of Weight Status as Outcome}

As with most studies on childhood overweight, our primary outcome parameter was change in BMI-SDS ('overweight'). However, we repeated our analyses using change in z-score of \%FM ('overfat') and WC ('overwaist') as alternative outcome parameters. We could show in the 4-year follow-up data that all 3 parameter were similarly effective regarding intervention and were also similarly associated with co-morbidities [13]. Thus all parameters seemed to be appropriate for risk assessment in children and adolescents. In the 8-year follow-up data, a significant effect of intervention was only reached using BMI-SDS, but the same directions of effect were seen for \%FM and WC (table 3). A converse effect regarding different outcome parameters used was also found in other studies. In the review of Doak et al. [5], 3 studies were effective regarding a reduction in BMI and skin folds, 2 studies were effective in BMI but not in skin folds, and 5 studies were effective regarding skin folds but not BMI. The more recent review of Brown et al. [2] found 2 studies that were effective according to BMI-SDS but not with respect to WC or skin folds. Studies using different outcomes have the advantage to provide a clearer picture of the intervention effect on body composition. In theory, an intervention focussing on physical activity may result in a reduction of skin folds concomitantly with no effect on BMI (reduction in fat mass and a concomitant increase in muscle mass). However, there is still no consensus on the most suitable parameter to characterize weight status in childhood due to a different accuracy of measurement (for BMI higher than for $\mathrm{WC}$ and \% FM) as well as possibly different long-term association with co-morbidities.

\section{Intervention Effect on Lifestyle Habits}

The KOPS data did not show a long-term effect of intervention on lifestyle habits (table 4). Since an effect of intervention in BMI-SDS was seen in students of high SES only, lifestyle data were also stratified according to SES. However, no effects became obvious in students of high SES. This may be due to the fact that the assessment of lifestyle habits was relatively poor as it is possible in epidemiological field studies only. These data were based on self-reports and measured as categorical variables (physical activity and media time) and qualitative food frequency. However, reproducibility and validity were proofed and assessed as acceptable (see methods). In addition, the aims of our intervention were to improve a healthy lifestyle in general and were not focussed on concrete lifestyle changes. The rationale of interventions on childhood obesity is that children are requested to improve lifestyle habits and as a result, an amelioration of weight status will be detected. Thus, changes in weight status are the primary outcome in most studies and long-term changes in lifestyle habits are rarely documented, at most in the short term in the context of a process evaluation. However, some studies showed concomitant changes in lifestyle habits as well as in weight status $[21,27]$. In other studies, lifestyle habits were improved but there was no effect on weight status [28, 29].

\section{Intervention Effect on Co-Morbidity}

BMI-SDS, z-score of WC and \%FM at age 14 years as well as 8 -year changes in these parameters were positively correlated blood pressure (see results). The latter finding confirms the impact of intervention on prevention of childhood overweight. This is in line with an American study on 6th-grade students where a high BMI was associated with cardiometabolic risk factors [30]. A recent study on American Indian children showed that childhood overweight and hypertension were associated with premature death from endogenous causes [31]. Regarding intervention, we did not observe a significant difference in blood pressure between I and NI students (table 5).

\section{Strengths and Limitations of the Study}

The strengths of this study include its use of longitudinal data over an 8-year time span, which up to now is unique for school-based intervention on childhood overweight. Furthermore, we used a multilevel approach to control for possible 
clustering effects of students within schools. Despite these strengths, this study had some limitations. We had a high dropout rate resulting in a bias towards normal weight subjects (table 1). However, we have used weight factors to adjust for this, and both intervention and non-intervention students were affected. The dropout rate was higher in NI and in I. This might be due to the fact that in each year some whole schools dropped out because of lack of time and/or limited personnel. Since we had up to 4 I schools and up to 29 NI schools per year, the probability that a NI school dropped out was higher than that for an I school. Thus, we do not think that there were different reasons for dropout at the individual level. In addition, the intention to treat analysis confirmed the effect of intervention in students of high SES families. The data were limited by inaccuracies of selfreported lifestyle habits, which may add to the 'no effect' of intervention. We cannot exclude that there was an exchange on information between teachers, parents and children of different schools or within schools of different age groups. However, we think that this would have a negligible effect on our outcome.

\section{Conclusion}

This 8-year follow-up study provides evidence that schoolbased health promotion has sustained effects and is effective in a subgroup of students from high SES families. However, the data argue in favour of further preventive measures in- cluding environmental and political involvement. Long-term surveillance is necessary to evaluate the sustainability of intervention programs in a school setting.

\section{Contributors}

SPD and MJM had the original idea, SPD did the statistical analyses and interpretation of the data, and wrote the paper. BL, DL, JS acquired data. MJM supervised the study, did the interpretation of the data and wrote the paper. All authors discussed the data and approved the final version of the paper. MJM will act as guarantor for the paper.

\section{Funding}

Deutsche Forschungsgemeinschaft (DFG Mü 5.1, 5.2, 5.3 und 5.5), 'Kompetenznetz Adipositas (Competence Network on Obesity)' funded by the Federal Ministry of Education and Research (FKZ: 01GI0821), WCRF, Wirtschaftliche Vereinigung Zucker. The sponsors of the study had no role in study design, data collection, data analysis, data interpretation, or writing of the paper. The corresponding author had full access to all the data in the study and had final responsibility for the decision to submit for publication.

\section{Disclosure Statement}

The authors declared no conflict of interest.

\section{References}

1 Whitlock EP, O'Connor EA, Williams SB, Beil TL, Lutz KW: Effectiveness of weight management interventions in children: a targeted systematic review for the USPSTF. Pediatrics 2010;125:e396-418.

2 Brown T, Summerbell C: Systematic review of school-based interventions that focus on changing dietary intake and physical activity levels to prevent childhood obesity: an update to the obesity guidance produced by the national institute for health and clinical excellence. Obes Rev 2009;10: 110-141.

$\checkmark 3$ Katz DL, O'Connell M, Njike VY, Yeh MC, Nawaz H: Strategies for the prevention and contro of obesity in the school setting: systematic review and meta-analysis. Int J Obes (Lond) 2008;32: 1780-1789.

4 Campbell K, Waters E, O’Meara S, Summerbell C: Interventions for preventing obesity in childhood A systematic review. Obes Rev 2001;2:149-157.

$\checkmark 5$ Doak CM, Visscher TL, Renders CM, Seidell JC: The prevention of overweight and obesity in children and adolescents: a review of interventions and programmes. Obes Rev 2006;7:111-136.

6 Sharma M: International school-based interventions for preventing obesity in children. Obes Rev 2007;8:155-167.

7 Plachta-Danielzik S, Pust S, Asbeck I, CzerwinskiMast M, Langnase K, Fischer C, Bosy-Westpha A, Kriwy P, Muller MJ: Four-year follow-up of school-based intervention on overweight children: the KOPS study. Obesity (Silver Spring) 2007;15: 3159-3169.
8 Marcus C, Nyberg G, Nordenfelt A, Karpmyr M, Kowalski J, Ekelund U: A 4-year, cluster-randomized, controlled childhood obesity prevention study: STOPP. Int J Obes (Lond) 2009;33:408-417.

-9 Kafatos I, Manios Y, Moschandreas J, Kafatos A: Health and nutrition education program in primary schools of Crete: changes in blood pressure over 10 years. Eur J Clin Nutr 2007;61:837-845.

10 Romon M, Lommez A, Tafflet M, Basdevant A, Oppert JM, Bresson JL, Ducimetiere P, Charles MA, Borys JM: Downward trends in the prevalence of childhood overweight in the setting of 12year school- and community-based programmes. Public Health Nutr 2008:1-8.

11 Muller MJ, Asbeck I, Mast M, Langnase K, Grund A: Prevention of obesity - more than an intention. Concept and first results of the Kiel obesity prevention study (KOPS). Int J Obes Relat Metab Disord 2001;25(suppl 1):S66-74.

12 Plachta-Danielzik S, Bartel C, Raspe H, Thyen U, Müller MJ: Assessment of representativity of a study population - experience of the Kiel obesity prevention study (KOPS). Obes Facts 2008;1:325330.

13 Plachta-Danielzik S, Landsberg B, Johannsen M, Lange D, Muller MJ: Association of different obesity indices with blood pressure and blood lipids in children and adolescents. Br J Nutr 2008;100:208218.
4 Kromeyer-Hauschild K, Wabitsch M, Kunze D, Geller F, Geiß H, Hesse V, von Hippel A, Jaeger U, Johnson D, Korte W, Menner K, Müller G, Müller MJ, Niemann-Pilatus A, Remer T, Schaefer F, Wittchen H-U, Zabransky S, Zellner K, Ziegler A, J. H: Perzentile für den Body Mass Index für das Kindes- und Jugendalter unter Heranziehung verschiedener Deutscher Stichproben. Monatsschr Kinderheilkd 2001;149:807-818.

15 Landsberg B, Plachta-Danielzik S, Much D, Johannsen M, Lange D, Muller MJ: Associations between active commuting to school, fat mass and lifestyle factors in adolescents: the Kiel obesity prevention study (KOPS). Eur J Clin Nutr 2008;62:739-747.

16 Grund A, Krause H, Siewers M, Rieckert H, Muller MJ: Is TV viewing an index of physical activity and fitness in overweight and normal weight children? Public Health Nutr 2001;4:1245-1251.

17 Report of the Second Task Force on Blood Pressure Control in Children - 1987. Task Force on Blood Pressure Control in Children. National Heart, Lung, and Blood Institute, Bethesda, Maryland, USA. Pediatrics 1987;79:1-25.

18 Flores R: Dance for health: improving fitness in African American and Hispanic adolescents. Public Health Rep 1995;110:189-193.

19 Mo-suwan L, Pongprapai S, Junjana C, Puetpaiboon A: Effects of a controlled trial of a schoolbased exercise program on the obesity indexes of preschool children. Am J Clin Nutr 1998;68:10061011. 
20 Sallis JF, McKenzie TL, Alcaraz JE, Kolody B, Faucette N, Hovell MF: The effects of a 2-year physical education program (spark) on physical activity and fitness in elementary school students. Sports, play and active recreation for kids. Am J Public Health 1997;87:1328-1334.

21 Gortmaker SL, Peterson K, Wiecha J, Sobol AM, Dixit S, Fox MK, Laird N: Reducing obesity via a school-based interdisciplinary intervention among youth: planet health. Arch Pediatr Adolesc Med 1999;153:409-418.

22 Haerens L, Deforche B, Maes L, Stevens V, Cardon G, De Bourdeaudhuij I: Body mass effects of a physical activity and healthy food intervention in middle schools. Obesity (Silver Spring) 2006;14: 847-854.

23 Sallis JF, McKenzie TL, Conway TL, Elder JP, Prochaska JJ, Brown M, Zive MM, Marshall SJ, Alcaraz JE: Environmental interventions for eating and physical activity: a randomized controlled trial in middle schools. Am J Prev Med 2003;24:209-217.
24 Webber LS, Osganian SK, Feldman HA, Wu M, McKenzie TL, Nichaman M, Lytle LA, Edmundson E, Cutler J, Nader PR, Luepker RV: Cardiovascular risk factors among children after a 2 1/2-year intervention - the CATCH study. Prev Med 1996; 25:432-441.

25 Muckelbauer R, Libuda L, Clausen K, Toschke AM, Reinehr T, Kersting M: Immigrational background affects the effectiveness of a school-based overweight prevention program promoting water consumption. Obesity (Silver Spring) 2010;18:528534.

26 Langnäse K, Asbeck I, Mast M, Müller MJ: Influence of socioeconomic status on long-term effect of family-based obesity treatment intervention in prepubertal overweight children. Health Education 2004;104:336-343.

27 Robinson TN: Reducing 's television viewing to prevent obesity: a randomized controlled trial. JAMA 1999;282:1561-1567.
8 Luepker RV, Perry CL, McKinlay SM, Nader PR, Parcel GS, Stone EJ, Webber LS, Elder JP, Feldman HA, Johnson CC, et al.: Outcomes of a field trial to improve children's dietary patterns and physical activity. The child and adolescent trial for cardiovascular health. CATCH collaborative group. JAMA 1996;275:768-776.

29 Donnelly JE, Jacobsen DJ, Whatley JE, Hill JO, Swift LL, Cherrington A, Polk B, Tran ZV, Reed G: Nutrition and physical activity program to attenuate obesity and promote physical and metabolic fitness in elementary school children. Obes Res 1996;4:229-243.

30 Jago R, Drews KL, McMurray RG, Thompson D, Volpe SL, Moe EL, Jakicic JM, Hoang T, Bruecker S, Blackshear TB, Yin Z: Fatness, fitness, and cardiometabolic risk factors among sixth grade youth. Med Sci Sports Exerc 2010;42:1502-1510.

31 Franks PW, Hanson RL, Knowler WC, Sievers ML, Bennett PH, Looker HC: Childhood obesity, other cardiovascular risk factors, and premature death. N Engl J Med;362:485-493. 